\title{
Educação Matemática e Ideologia
}

\author{
Andréa Thees \\ Universidade Federal do Estado do Rio de Janeiro \\ andreathees@gmail.com
}

\section{Resumo}

A pesquisa de doutorado "Práticas profissionais de professores de matemática mediadas pelo audiovisual", que está sendo desenvolvida no âmbito do Programa de Pós-Graduação em Educação da Universidade Federal do Estado do Rio de Janeiro, encontra-se em fase preliminar dos estudos bibliográficos e revisão de literatura. Pretendemos analisar como se desdobram as práticas docentes mediadas pelo audiovisual, de professores de matemática que lecionam na Educação Básica, através de uma pesquisa qualitativa, por meio de uma etnografia virtual como metodologia. Neste recorte, utilizamos como aporte teórico alguns autores alinhados com a teoria social marxiana, com a Etnomatemática e com a Educação Matemática Crítica. Como resultados parciais, apresentaremos indícios de como a relação entre a Educação Matemática e a Ideologia pode ser interpretada sob o ponto de vista sociopolítico.

Palavras-chave: Ideologia. Etnomatemática. Educação Matemática Crítica.

\section{Mathematics Education and Ideology}

\begin{abstract}
The Doctorate research "Professional practices of math teachers mediated by audiovisual", being developed in the scope of the Post-Degree Program in Education from the Universidade Federal do Estado do Rio de Janeiro, is currently at an early stage of bibliography studies and literature review. We aim to analyze how the teachers' practices mediated by audiovisual unfold, using a qualitative research, applying a virtual ethnography as methodology. In this paper, we use as theoretical framework some authors aligned with Marxist Social Theory, Ethnomathematics and Critical Mathematics Education. As partial results, we will present clues of how the relationship between Mathematics Education and Ideology can be presented from a sociopolitical standpoint.
\end{abstract}

Keywords: Ideology. Etnomathematics. Critical Mathematics Education.

\section{Introdução}

Refletir sobre as questões impostas pela ideologia dominante no ensino e aprendizagem de matemática parece ser extremamente pertinente, seja quando analisamos o currículo vigente ou até mesmo quando pensamos nas práticas profissionais dos professores, em salas de aula ou fora delas. 
Apesar das diversas pesquisas empreendidas até o momento, ainda se verifica o tratamento dado erroneamente ao conteúdo matemático como produto acabado, que apresenta o conhecimento sempre como verdade absoluta, elaborado por mentes privilegiadas, desprovidas de interesses político-econômicos e ideológicos, ou seja, desvinculado do contexto histórico, social e cultural.

Cabe destacar que a compreensão dos termos 'ideologia' e 'ideológicos' que será utilizada aqui se origina na concepção marxiana, segundo a qual o papel e o poder da ideologia seriam os de naturalizar ideias e impor as vontades das classes dominantes.

As ideias (Gedanken) da classe dominante são, em cada época, as ideias dominantes; isto é, a classe que é a força material dominante da sociedade é, ao mesmo tempo, sua força espiritual dominante. A classe que tem à sua disposição os meios materiais de produção dispõe, ao mesmo tempo, dos meios de produção espiritual, o que faz com que a ela sejam submetidas, ao mesmo tempo e em média, as ideias daqueles aos quais faltam os meios de produção espirituais. As ideias dominantes nada mais são do que a expressão ideal das relações materiais dominantes, as relações materiais dominantes concebidas como ideias; portanto, a expressão das relações que tornam uma classe a classe dominante são as ideias da sua dominação. (MARX; ENGELS, 1987, p. 72)

Nesta visão, os autores situam o surgimento da ideologia no processo da divisão social do trabalho, próprio do modo de produção capitalista, que separa as atividades em material e intelectual. Segundo Marx e Engels (1987), a dominação entre as classes surge na divisão dos homens entre proprietários e não proprietários dos meios de trabalho. Para manter o privilégio do poder político e econômico do primeiro grupo sobre o segundo são necessários dois meios de controle social, o Estado e a ideologia.

Além de deter o poder sobre os meios de produção, a classe dominante necessita também aparentar ser a classe dos pensadores e produtores de ideias. Para que o processo ideológico ocorra efetivamente, os membros da sociedade devem se identificar com suas características, considerando-as comuns e aceitáveis. A naturalização desta ideologia se dá, então, pela distribuição das ideias através dos meios de comunicação, da religião, dos costumes e da educação. Seu caráter dominador e de controle social passam a ser vistos por todos (dominantes e dominados) como naturais e corretos.

Neste contexto, busca-se refletir sobre a relação entre Educação Matemática e ideologia, dentro das perspectivas sociais, políticas, econômicas e culturais. Para isso, pretende-se traçar um breve percurso desde a sua origem, como campo de pesquisas, até os aportes teóricos situados nas tendências em Educação Matemática acerca da sua dimensão crítica (SKOVSMOSE, 2007) e sociocultural (D’AMBROSIO, 2002, 2009, 2011, 2013). Tais apropriações parecem reforçar as suposições de que algumas ações na Educação Matemática podem ser capazes de romper com o seu caráter de ocultamento do real e de neutralização da dominação. 


\section{A Educação Matemática e sua origem na Alemanha}

Apesar de ser bem mais recente no Brasil, a preocupação com a Educação Matemática começou na transição do século XIX para o século XX, a partir do momento em que se intensificaram a industrialização e a competição entre impérios. Segundo a interpretação de D’Ambrosio (2013, p. 31), a motivação para o surgimento da Educação Matemática tem um importante componente político, evidenciado quando se percebeu que a ampliação de um império dependia do seu desenvolvimento científico e tecnológico, o qual, por sua vez, dependia de engenheiros e de cientistas. Todavia, formar engenheiros e cientistas demandava uma preocupação em preparar melhor os alunos em matemática.

Por outro lado, a revolução industrial levou a um enorme aumento das populações urbanas. Habilidades matemáticas básicas, tais como a capacidade de organizar o tempo, contar dinheiro e realizar cálculos aritméticos simples, tornou-se essencial neste novo estilo de vida urbano. Dentro dos novos sistemas públicos de educação e em todos os países desenvolvidos, a matemática tornouse uma disciplina central do currículo desde o início da escolarização, seja para formar cientistas e engenheiros, seja para atender aos interesses das sociedades.

Embora a Educação Matemática tenha se estabelecido apenas mais tarde como um campo independente de pesquisa na maior parte dos países da Europa, foi primeiramente na Alemanha que a área se desenvolveu institucionalmente. No final do século XIX, a Alemanha surge com grande força no cenário europeu, impulsionada pelo que se pode chamar de imperialismo cultural, que implicou em um grande desenvolvimento de ciência e tecnologia. Continuamente, as grandes indústrias alemãs emergentes necessitavam, na época, de melhor preparação de matemáticos em tecnologia avançada. Esta necessidade passou a ser uma política de prioridade nacional e acredita-se que tenha sido esta a razão que motivou um importante matemático alemão a se envolver intensamente com a Educação Matemática (D’AMBROSIO, 2013, p. 32).

Felix Klein (1849 - 1925), cuja mãe, Elise Sophie Kayser, pertencia a uma família de industriais alemães, e cujo pai, Caspar Klein, era oficial do governo alemão, nasceu em Düsseldorf na Alemanha. Klein talvez tenha sido o primeiro a atuar e a escrever sistematicamente sobre a área, criando uma disciplina de Ensino de Matemática na Universidade de Göttingen em 1893 e, logo depois, criando Internacional Commission on Mathematical Instruction - ICMI, em 1908. Desde sua criação até 1920, o matemático visitou diversos países da Europa trabalhando em uma pesquisa cujo objetivo era mapear a evolução do ensino de matemática.

$\mathrm{Na}$ biografia de Klein (SOUZA, 2010) podem-se encontrar sinais de suas crenças no idealismo alemão de Hegel, como na famosa frase de sua autoria: "Felizes aqueles que se divertem com problemas que educam a alma e elevam o espírito.”. Ao que tudo indica o matemático alemão, 
que impulsionou a Educação Matemática em seus primórdios, parecia estar mais preocupado com o campo das ideias matemáticas do que em compreender a matemática como uma construção humana. Curiosamente, em 1875, Klein casou-se com Anne Hegel, neta do filósofo Georg Hegel.

Sob a influência da ideologia alemã, a Educação Matemática chegou ao Brasil no início do século XX através das publicações de Felix Klein que foram adotadas por alguns professores do Colégio Pedro II, em especial por Euclides Roxo (SOUZA, 2010, p. 45). A concepção da matemática como abstrata e descolada da realidade fica evidente quando Souza (2010) destaca que

Roxo lembra ainda que procurou, tanto nas diretrizes quanto em seus livros, fazer do aluno um pesquisador, partindo sempre da intuição no ensino de conceitos matemáticos. Cita que 'o ensino se fará, assim, pela solicitação constante da atividade do aluno (método heurístico), de quem se procurará fazer um descobridor e não receptor passivo de conhecimento'. Continua sua explicação enfatizando que não procura com essa publicação preparar alunos para exames, muito menos para decorar regras e definições, e sim contribuir para que este alcance o 'aperfeiçoamento de sua cultura espiritual pelo conhecimento dos processos matemáticos’. (Ibidem, p. 56)

Não obstante ser possível notar certa preocupação com a não passividade do aluno fazendo com que ele seja descobridor do seu próprio conhecimento, ao enfatizar a cultura espiritual do estudante, Roxo demonstrava estar conservando a mesma ideologia de Klein. Para ambos os matemáticos, a questão do saber era teórica e cabia ao pensamento humano, enquanto que para Marx (1987, p. 11) "é na práxis que o homem deve demonstrar a verdade, isto é, a realidade e o poder, o caráter terreno de seu pensamento”, ou seja, o conhecimento é verdadeiro se puder ser comprovado na prática.

Contudo, somente mais tarde, ao publicar seus próprios livros, Euclides Roxo demonstra uma maior preocupação em valorizar alguns dos aspectos históricos da matemática. A cada encerramento de capítulo, é incorporado um texto relacionado à história da matemática e biografias de matemáticos de cada época. Porém, as tentativas de valorizar as relações entre a matemática e os contextos histórico, social e cultural ainda eram bastante incipientes se comparadas a algumas tendências mais recentes em Educação Matemática.

Para Pais (2012, p. 65), nas últimas duas décadas houve um aumento considerável de pesquisas em Educação Matemática com foco nas questões de equidade e justiça social. Apesar da proliferação destas temáticas nas pesquisas, ainda persiste a ideia de um campo que tem estado historicamente preocupado com questões voltadas à melhoria do processo de ensino e aprendizagem de matemática nas escolas, o que acaba reduzindo os objetivos de grande parte das pesquisas ao desenvolvimento de métodos instrucionais que visam o sucesso dos alunos. Pais (2012, p. 65) concorda que as pessoas necessitam saber matemática para exercerem sua cidadania, ou seja, serem socialmente incluídas. Não obstante, o autor alerta que possuir conhecimento e competência 
matemáticos não estaria relacionado com esta necessidade social, mas sim com a valorização escolar dada para aqueles que sabem matemática.

Pessoas precisam da matemática escolar não porque a utilizam diretamente na participação democrática (como conhecimento e competência), mas para continuar tendo sucesso na escola, realizar um curso universitário e encontrar um emprego estável e, assim, se tornarem seres sociais normais. Afirmo que a importância da matemática precisa ser discutida não como um campo de conhecimento, mas como um campo de valor. Portanto, torna-se necessário sustentar a argumentação de que as pessoas realmente não usam a matemática escolar no exercício da cidadania ou como trabalhadores. (PAIS, 2012, p. 65-66)

São reflexões extremamente importantes para se pensar a Educação Matemática em outro contexto. Cabe ressaltar que, quando não se pensa em abordar questões mais amplas que envolvem as estruturas sociais e políticas, a atuação da Educação Matemática enquanto campo de pesquisa poderá se tornar ineficiente no que diz respeito às mudanças sociais que almejamos.

Desde sua concepção na Alemanha, parece que a Educação Matemática continua sustentando uma ideologia que está exclusivamente a serviço de modernizar o ensino e incorporar técnicas para atingir os nobres objetivos de democratização do ensino. Todavia, na verdade, as investigações do campo acabam condicionadas para atender os interesses de um sistema educativo direcionado à produção de mão de obra qualificada, a fim de manter as relações de poder estagnadas. Isto representa uma das mais desprezíveis consequências da ideologia, ou seja, a necessidade de que não seja percebida, de que aparente ser "natural", pois caso seja exposta, poderia ser combatida. Ao permanecer oculta atrás de uma falsa concepção de Educação Matemática, a ideologia se mantém intacta, impedindo questionamentos acerca das relações de poder e reforçando a ideia de universalidade e de certeza matemáticas.

\section{A Educação Matemática nas perspectivas da Etnomatemática e da Educação Matemática Crítica - EMC}

Por razões várias, ainda pouco explicadas, a civilização ocidental, que resultou da interação de várias culturas antigas, veio a se impor a todo o planeta. Com essa hegemonia, aquela matemática, cuja origem remonta às civilizações mediterrâneas, particularmente à Grécia antiga, também se impôs a todo o mundo. Greer e Mukhopadhyay (2012, p. 229) nos alertam para as diversas formas de dominação e eliminação de alguns grupos por outros e de como a matemática e a educação matemática influenciaram nestes processos. Independente se dentro ou fora da escola, a matemática vem sendo usada para comunicar a inferioridade intelectual de determinados grupos ou indivíduos, fortalecendo a crença de que uns são superiores aos outros e, por isso, estes últimos devem se conformar e submeter à ordem hegemônica estabelecida pelos primeiros. 
Uma afirmação muito frequente é que a matemática é uma só, é universal. Segundo D’Ambrosio (2002, p.8), essa questão é muito bem abordada pelo historiador Oswald Spengler ${ }^{1}$, em 1918, num certo sentido chamando a atenção para a etnomatemática ao dizer que não "há uma escultura, uma pintura, uma matemática, uma física, mas muitas, cada uma diferente das outras na sua mais profunda essência, cada qual limitada em duração e autossuficiente".

A matemática, vista apenas como uma ciência exata, transformou-se numa disciplina perversa e excludente ao negar uma concepção mais abrangente do mundo, desconhecendo seu papel nas diversas manifestações culturais, desvalorizando a relação entre cultura e educação matemática. A esta concepção universal, associa-se também o controle ideológico que se manifesta nos currículos, nos livros didáticos, na formação inicial e continuada de professores. Este fenômeno abrange várias ações, desde a seleção dos conteúdos, até a transmissão dos valores culturais matemáticos: seu realismo, objetividade, controle, progresso e mistério.

Mesmo considerando a enorme diversidade humana, cada comunidade ou sociedade tende a controlar o comportamento de seus indivíduos, uma vez que as relações desta comunidade dependem da imposição de um conjunto de regras e limites. Para Verdejo (2004), este conjunto de ações limitadoras e sua implicação nas práticas sociais constituem uma cultura.

Ainda para o autor, pode ocorrer também que, em uma determinada cultura

a matemática utilizada como uma linguagem, como uma ferramenta de pensamento se constitui como um indicador cultural, que possui um conjunto de conceitos a partir dos quais uma dada população age e pensa. (VERDEJO, 2005, p. 394)

Para Ubiratan D'Ambrosio ${ }^{2}$ “desde pequena a criança é condicionada a achar que a matemática é complicada"; o autor acrescenta que "se ela tem em casa um irmão mais velho, já ouve que matemática é difícil”. É com este comportamento condicionado que a criança entra na escola "apavorada" com a disciplina, quando o natural seria a matemática ser tratada como um conhecimento presente em todas as coisas do cotidiano das pessoas de maneira espontânea. Este discurso se repete durante toda a vida escolar e prossegue encontrando eco também na vida profissional.

A visão de D’Ambrosio se assemelha àquela compartilhada por Roland Barthes em relação aos mitos. Para Barthes (2001, p. 131), "o mito é um sistema de comunicação, é uma mensagem” que, por ser um fala roubada, esvaziada de seu conteúdo histórico, da sua essência sociopolítica, “tem a função de deformar, não fazer desaparecer” (ibidem, p. 143). Quando a etnomatemática

\footnotetext{
${ }^{1}$ Oswald Spengler: The Decline of the West. Volume I: Form and Actuality, trans. Charles Francis Atkinson (orig.ed.1918), Alfred A. Knopf Publisher, New York, 1926; p.21.

${ }^{2}$ Entrevista concedida à Revista Diário na Escola - Santo André. Publicação: 31 out 2003.
} 
procura desmistificar outras formas de pensar, sem deformar nem fazer desaparecer os conhecimentos de natureza matemática, tem-se que

a educação nessa transição não pode focalizar a mera transmissão de conteúdos obsoletos, na sua maioria desinteressantes e inúteis, e inconsequentes na construção de uma nova sociedade. O que podemos fazer para as nossas crianças é oferecer a elas os instrumentos comunicativos, analíticos e materiais para que elas possam viver, com capacidade de crítica, numa sociedade multicultural e impregnada de tecnologia. (D’AMBROSIO, 2009, p. 46)

Contudo, numa proposta etnomatemática de ensino, não caberia a rejeição da matemática acadêmica nem trataria de ignorar conhecimentos e comportamentos modernos, mas sim, incorporar a eles valores de humanidade, sintetizados numa ética de respeito, solidariedade e cooperação. “Conhecer e assimilar a cultura do dominador se torna positivo desde que as raízes do dominado sejam fortes. Na educação matemática, a etnomatemática pode fortalecer essas raízes." (D’AMBROSIO, 2009, p.43).

Não são raras as discussões sobre a utilidade da matemática e a importância de se ensinar matemática. Diversas questões são analisadas nestas discussões, entre elas as proposições de que a matemática provê um recurso crucial para transformações sociais ou de que a matemática não tem relevância social. Para D’Ambrosio (2009, p. 46),

a matemática se impôs com forte presença em todas as áreas de conhecimento e em todas as ações do mundo moderno. Sua presença no futuro será certamente intensificada, mas não a praticada hoje. Será, sem dúvida, parte integrante dos instrumentos comunicativos, analíticos e materiais.

De forma contundente, Skovsmose (2007) também afirma que a matemática está situada no núcleo do desenvolvimento social e esta centralidade será aumentada no futuro. Realmente, grandes avanços no conhecimento da natureza e no desenvolvimento de novas tecnologias, embora nem sempre positivos para todos na sociedade, têm sido noticiados e presenciados nos últimos anos. Paralelo a estes avanços, ou retrocessos, está o papel crucial da matemática que, portanto, deveria ser considerado na interpretação de diversos fenômenos sociais. Para o autor,

do mesmo modo que letramento, a matemácia se refere a diferentes competências. Uma delas é lidar com noções matemáticas; uma segunda é aplicar essas noções em diferentes contextos; a terceira é refletir sobre essas aplicações. (...) Um significado direto de poder refere-se às possibilidades de um indivíduo ultrapassar as limitações que uma situação sociopolítica impôs a um grupo de pessoas. De forma mais geral, matemácia significa um suporte para o cidadão crítico, bem como para qualquer grupo de pessoas que nós tenhamos em mente. (SKOVSMOSE, 2007, p. 74-75).

Para o autor, a matemática ocupa um papel relevante no desenvolvimento social e tecnológico que não pode ser ignorado. Ao tentar observar a matemática na sociedade, Skovsmose (2007, p. 32) apresenta o conceito de matemática em ação. As incertezas de tal forma de ação 
revelam "a necessidade de reflexão e crítica sobre qualquer forma de atividade matemática, e isso se torna um desafio à Educação Matemática".

A educação matemática crítica procura potencializar o desenvolvimento de temas sociais em apoio aos ideais democráticos. Todavia, "como ela pode operar em relação aos ideais democráticos dependerá do contexto, da maneira como o currículo é organizado, do modo como as expectativas dos estudantes são reconhecidas, etc.” (SKOVSMOSE, 2007, p. 72), estando a questão da ideologia no cerne do debate para uma atuação docente alinhada às tendências da Educação Matemática Crítica e da Etnomatemática.

Sendo assim, é fundamental o professor ter conhecimento de si próprio e de sua assunção ideológica. Segundo D’Ambrosio (2011, p. 108), “ninguém pode pretender influenciar outros sem ter o domínio de si próprio". Além disso,

o professor deve conhecer a sociedade em que atua e ter uma visão crítica dos seus problemas maiores, bem como de seu ambiente natural e cultural, e da sua inserção numa realidade cósmica. O professor deve estar livre de preconceitos e predileções. Só sendo livre poderá permitir que outros sejam livres. Em vez de fazer com que o aluno aprenda o que ele, professor, sabe, deve criar situações para que o aluno queira ir além do conhecimento do professor. E sobretudo para que ele procure saber sobre a realidade que o cerca e tenha liberdade para encontrar significação no seu ambiente. (Ibidem)

Neste processo está implícito vivenciar um sistema de valores no cotidiano que, muitas vezes, pode implicar em desobedecer a ordens e normas de conduta escolares. A desobediência coletiva deflagra as ações de grupos e os movimentos sociais. Individualmente, a desobediência valida o exercício da livre vontade do ser humano (D’AMBROSIO, 2011, p. 236). Coletivamente, a desobediência desconstrói a ideologia hegemônica.

\section{Conclusões parciais}

Fortalecer uma prática em Educação Matemática, que considera incluir como conteúdo curricular as questões socioculturais, implica na efetivação de um processo educativo humanista e emancipatório pautado na sociedade e na cultura. Trata-se de uma prática voltada à percepção do caráter ativo, indagador e pesquisador do educando, assumindo sua consciência reflexiva e crítica, possibilitando-o desempenhar um papel importante na interação com muitos outros fatores e atores sociopolíticos.

Frente a essas questões, as contribuições do Programa Etnomatemática e da Educação Matemática Crítica podem acarretar uma mudança na ideologia, fazendo com que a Educação Matemática incentive a construção da liberdade ética e intelectual dos envolvidos, ou seja, da sua 
autonomia. Enquanto ser político, que possa validar sua participação na transformação da sociedade.

Consciente da sua livre vontade o professor é capaz de construir uma prática letiva na qual conhecimento e comportamento encontram-se em harmonia, superando dificuldades e enfrentando os desafios que certamente irão surgir. No processo educativo, qualquer opção pedagógica comporta um componente ideológico. Isto é verdade não somente nas disciplinas das áreas de humanas, que possuem maior conteúdo social, como geografia, história ou sociologia e filosofia, mas também, na matemática, uma disciplina tradicionalmente considerada como um modelo de imparcialidade ou de um ceticismo ideológico. Precisamente na Educação Matemática, durante a escolha de uma metodologia, já está implícita uma opção ideológica e pode-se perceber que existe uma ideologia, ou ainda mais de uma ideologia, que tem sido implicitamente transmitida através de processos educacionais diversos em contextos distintos, tanto nas salas de aula, quanto nas redes sociais.

Destas reflexões iniciais sobre a relação entre a Educação Matemática e a ideologia, podese inferir que, ao procurar analisar as práticas profissionais de professores de matemática mediadas pelo audiovisual, também estaremos nos perguntando: para que serve a educação matemática? Que conhecimentos matemáticos são selecionados para serem transmitidos? Quem os seleciona? Quem tem acesso às formas legítimas de conhecimento? A que interesses servem estes conhecimentos? Que relações sociais, políticas e econômicas influenciam a relação entre professores e estudantes?

A busca por respostas a estas indagações, e a outras que certamente irão surgir, talvez nos ajude a conceber a educação matemática como um processo dinâmico através do qual são estabelecidas noções fundamentais sobre a sociedade em vivemos, ou ainda, que o conjunto de práticas que atualmente chamamos de "educação matemática" são na verdade originadas em complexos sistemas sociais, políticos, econômicos e culturais.

\section{Referências}

BARTHES, R. Mitologias. Rio de Janeiro: Bertrand Brasil, 2001.

D’AMBROSIO, U. Etnomatemática e educação. Reflexão e Ação: Revista do Departamento de Educação. Santa Cruz do Sul: EDUNISC, v. 10, n. 1, p. 7-19, 2002. Disponível em: <http://etnomatematica.org/articulos/reflexao101.pdf>. Acesso em: 05/09/2016.

. Etnomatemática: elo entre as tradições e a modernidade. Belo Horizonte: Autêntica Editora, 2009.

. Educação para uma sociedade em transição. Natal: EDUFRN, 2011.

. O contexto internacional do surgimento da Educação Matemática e a fundação da SBEM. In: MUNIZ, N. C. Relatos e memórias: a trajetória histórica de 25 anos da Sociedade Brasileira de Educação Matemática (1988-2013). São Paulo: Editora Livraria da Física, 2013. cap. 1, p. 25-60. 
GREER, B.; MUKHOPADHYAY, S. The hegemony of mathematics. In: GREER, B.; SKOVSMOSE, O. (Eds.). Opening the cage: critique and politics of mathematics education. Rotterdam: Sense, 2012. cap. 10, p. 229-248.

HALSTED, G. B. Biography: Felix Klein. The American Mathematical Monthly, v. 1, n. 12, p. 417-420, 1894. Disponível em: <www.jstor.org/stable/2969034>. Acesso em: 05/09/2016.

MARX, K.; ENGELS, F. A ideologia alemã: crítica da mais recente filosofia alemã representada por Feuerbach, B. Bauer e Stirner, e do socialismo alemão representado por seus diferentes profetas. São Paulo: Editora Hucitec, 1987.

PAIS, A. A critical approach to equity in mathematics education. In: GREER, B.; SKOVSMOSE, O. (Eds.). Opening the cage: critique and politics of mathematics education. Rotterdam: Sense, 2012. cap. 2, p. 49-92.

VERDEJO, A. J. Ideología y Educación Matemática: el proceso de infusión ideológica. Espanha: Octaedro, 2004. . Ideología y Educación Matemática: el proceso de infusión ideológica. Epsilon - Revista de la Sociedad Andaluza de Educación Matemática "Thales", Espanha, n. 63, p. 393-396, 2005. SOUZA, G. M. Felix Klein e Euclides Roxo: debates sobre o ensino da matemática no começo do século XX. Dissertação de Mestrado. Universidade Estadual de Campinas. Instituto de Matemática, Estatística e Computação Científica, Campinas, SP, 2010.

SKOVSMOSE, Ole. Educação crítica: incerteza, matemática, responsabilidade. Tradução de Maria Aparecida Viggiani Bicudo. São Paulo: Cortez, 2007. 